\title{
Editorial
}

\section{Protecting the Antarctic - the Protocol becomes law}

W e should all be really pleased both with ourselves and with our governments for the amazingly rapid progress the Protocol on Environmental Protection to the Antarctic Treaty has made. Final ratification by twenty six countries in less than seven years is impressive for an international treaty with such wide obligations.

The Protocol has introduced new definitions of how and why we should attempt protection, new structures-notably the Committee for Environmental Protection(CEP) that will advise and formulate recommendations to the Antarctic Treaty Parties in connection with the implementation of the Protocol - and finally a more proactive requirement to limit more effectively our general impacts on the whole environment. All this is good but there are still significant unresolved problems that will need to be addressed.

At the highest level it must be accepted that modern conservation is an active undertaking, not preservation for its own sake, and that the Protocol apparently allows for active management of areas, communities and species to meet conservation objectives. This is still a novel concept for many in the Antarctic but it is accepted as fundamental to successful conservation elsewhere in the world. Equally important is finding ways to ensure that 'dependent ecosystems' are not ignored simply because the animals inconveniently travel outside the Treaty area when foraging. Political boundaries have always been difficult for animals to recognize!

Good conservation recognizes when species need special protection and when it is no longer appropriate. It is seems unnecessary to continue affording specially protected status to the fur seal that now has a population of well over one million animals. Removing protection to such species is a signal that conservation measures work! We should also be actively looking to see if other species need special protection.

The adoption of mandatory management plans for all Specially Protected Areas is a great step forward. However, experience elsewhere in the world suggests that simply making the legal declaration can be inadequate in providing the protection sought. It is necessary to check regularly to ensure that use of the Area has not inadvertently undermined the objectives for which protection was originally declared. If we fail in this we will be short-changing our scientific opportunities for the future. The scientific community needs to find an effective way to ensure that adequate data are collected and made available on the use of these areas.

The Antarctic Treaty Parties have recognized the need for a short workshop on Antarctic Specially Protected Areas and this will be held before the Tromsø Treaty Meeting. The agenda will address some of these problems but not all. Let us all recognize that the full participation of the scientific community in the workshop and in the discussions of the CEP, both through SCAR representation and through advice to national delegations, is important in protecting the scientific value of the Antarctic. Most of the major conservation initiatives and almost all of the hard work in this field over the last 30 years has originated within the scientific community. The CEP now offers us further opportunities to contribute to the continuing improvement of management of the Antarctic environment.

DAvid W.H. WaLtoN 